Research Article

\title{
Mechanism and Control of Roadway Floor Rock Burst Induced by High Horizontal Stress
}

\author{
Dongming Guo $\mathbb{D}$, ${ }^{1}$ Xinchao Kang $\mathbb{D},{ }^{1}$ Zhiying Lu $\left(\mathbb{D}\right.$, ${ }^{2}$ and Qiyu Chen $\mathbb{D}^{1}$ \\ ${ }^{1}$ School of Mechanics and Civil Engineering, China University of Mining and Technology (Beijing), Beijing 100083, China \\ ${ }^{2}$ Jiangsu Haosen Architectural Design Co., Ltd, Changzhou 213000, Jiangsu, China \\ Correspondence should be addressed to Xinchao Kang; k_xinchao@163.com
}

Received 8 May 2021; Revised 10 June 2021; Accepted 24 June 2021; Published 5 July 2021

Academic Editor: Xiaowei Feng

Copyright (c) 2021 Dongming Guo et al. This is an open access article distributed under the Creative Commons Attribution License, which permits unrestricted use, distribution, and reproduction in any medium, provided the original work is properly cited.

\begin{abstract}
According to the characteristics of rock burst of high horizontal stress roadway floor, the rock burst mechanism of roadway floor was studied with the background of south track roadway Xing'an mine. Based on the deflection theory and energy principle of the slab, the mechanical model of the floor of the roadway under high horizontal stress was established, the stress and energy criteria of rock burst occurred in the floor of the roadway were deduced, the prevention and control measures of the floor pressure relief with large diameter borehole and concrete-filled steel tube pile support were put forward, and the key parameters were determined. By establishing a numerical model, the evolution law of plastic zone, horizontal stress, and elastic strain energy density of roadway floor with or without support is contrastively analyzed. The results show that the effective means to prevent and control the floor rock burst is to cut off the stress transfer path by weakening the hard floor to reduce floor energy accumulation so as to reduce the floor rock burst risk. Based on the above research, field tests were carried out, and the microseismic monitoring results showed that the floor pressure relief of large diameter boreholes and concrete-filled steel tube pile support effectively relieved the floor rock burst and guaranteed the safety and efficiency of roadway excavation. This technology can provide a reference for the prevention and control of floor rock burst of similar roadways.
\end{abstract}

\section{Introduction}

In all kinds of disasters faced by deep mining, rock burst, presents great destructive power [1-3]. The wide distribution of rock burst has attracted the attention of many scholars at home and abroad. Rock burst usually occurs in the form of elastic energy suddenly and violently released. With the increase of mining depth, rock burst accidents become more and more serious due to the increase of horizontal stress, resulting in huge economic losses.

In terms of the mechanism of rock burst, many scholars have carried out in-depth research on the mechanism of floor rock burst under dynamic load. Qi et al. [4] discussed the key scientific and technological issues in the prevention and control of deep coal and rock dynamic disasters and put forward the idea of multiscale and multisource prevention and control of deep coal and rock dynamic disasters. Zhao et al. [5] used the theory of small deflection of elastic thin plate to analyze the stress of roadway floor, and the main influencing factors of floor rock burst were studied, and the mechanism of floor broken blasting was analyzed. Xu et al. [6] analyzed the characteristics of floor rock burst in the roadway, put forward the concept of the risk coefficient of floor rock burst, and discussed its control method. Jiang et al. [7] analyzed the fault parameters in numerical simulations and rock burst potential of the floor surrounding rocks due to mining activities and provided a method for the fault parameters. Lijun [8] analyzed the characteristics and occurrence process of rock burst under the condition of hard floor rock, put forward the rock burst theory of regional imbalance of compression deformation, and put forward the corresponding rock burst prevention measures. In conclusion, the above studies have expounded the mechanism of floor rock burst from the perspective of stress and energy 
and put forward the starting criterion of floor rock burst, respectively. However, there is still a lack of specific research on floor burst caused by horizontal stress.

In the aspect of floor rock burst prevention and control, the integrated technology of dynamic load is developed, which is referred to as "drill-cutting-fracturing." The main advantage of this technology is the use of floor holes forming $300 \mathrm{~mm}$ super large diameter unmanned drilling. Liu et al. [9] summarized the rigid-flexible integrated energy absorbing support technology for deep rock burst based on the experience of rock burst prevention and control in Yuejin mine. Pan et al. [10] developed a roadway anti-impact hydraulic support with energy absorption function and a selfmoving roadway advance support, which has been applied in some mines onsite. In the rock burst roadway support, Yao et al. [11] proposed a new support technology using combined bolt-aluminum foam to prevent roadway rock burst and provided a theoretical basis for roadway rock burst prevention by combining bolt and aluminum foam. Wang et al. [12], taking a typical coal bursting mine in Yima Coalfield as the engineering background, studied the affordable ultimate load from overlying strata and applicable ultimate depth of U-shaped steel support. The research results of the above scholars achieved better prevention and control effects in the roadway of rock burst. However, these studies are mainly based on the occurrence conditions or principles of rock burst itself, lack of support for floor rock burst.

Therefore, based on the engineering background of floor rock burst induced by the excavation of south track roadway in Xing'an mine, this paper derived the floor rock burst instability stress and energy criteria under high horizontal stress on the basis of the deflection theory and energy principle of the slab and proposed the support method of large diameter borehole pressure relief in-floor combined with CFST pile. Furthermore, the prevention and control mechanism of floor rock burst of depressurization and support roadway is discussed in-depth, and field tests and verification are carried out.

\section{Engineering Profile}

Xing'an mine is located in the Hegang mining area, and the coal measure strata as a whole show a northeast trend. The tectonic stress field is controlled by the east-west stress field, and the regional in situ stress field is nearly east-west. The maximum and minimum principal stresses are located in the horizontal plane, and the intermediate principal stresses are located in the vertical plane. The coal mine is equipped with a transport track on the 18 floors of the four levels. The total length of the roadway is $1165 \mathrm{~m}$, the buried depth is $-830 \mathrm{~m}$, the tunnelling size is $4900 \mathrm{~mm}$ wide and $4700 \mathrm{~mm}$ high, and the net section is $15.87 \mathrm{~m}^{2}$. The roadway occurs in mudstone, sandy mudstone, and medium sandstone strata.

By analyzing the in situ stress test results, it can be seen that the horizontal tectonic stress in the area where the roadway is located is up to $34.72 \mathrm{MPa}$ is 1.65 times that of the vertical stress. The floor rock of the roadway is in a high horizontal compression stress environment, and there is large deformation in the side and floor of the roadway, as shown in Figure 1. The test results of bursting liability are shown in Table 1 . In Table $1, R_{\mathrm{c}}$ refers to uniaxial compressive strength; $K_{\mathrm{E}}$ refers to bursting energy index; DT refers to duration of dynamic fracture; $W_{\mathrm{ET}}$ refers to the elastic strain energy index. In the process of working face track roadway excavation, the production environment is shown as severe mine pressure and serious floor heave, and there are dynamic pressure phenomena in the roadway. Roadway layout and horizontal stress direction are shown in Figure 2 .

\section{Rock Burst Mechanism of Floor under High Horizontal Stress}

3.1. Analysis of Critical Stress of Floor. After excavation, the overburden is transferred to the floor through two sides, and the horizontal stress is higher than the initial stress [13]. Under the action of high horizontal stress, the floor deflects and accumulates a lot of strain energy, which is easy to induce floor rock burst. Therefore, the horizontal stress of the floor plays an important role in-floor rock burst. In order to study the start-up mechanism of rock burst under the flexural deformation of the floor, a mechanical model was established, as shown in Figure 3.

In Figure 3, $\mathrm{h}$ means the thickness of rock which has large deformation at the floor, $\omega$ means the deflection deformation of floor, and $L$ means the width of the floor. Compared with the roadway excavation length $y$, the thickness of rock strata with large deformation in floor is a smaller value $(h<<y)$; therefore, the mechanical model of the floor can be simplified to a planar thin plate deflection problem for discussion. According to the differential equation of elastic surface [14], the deflection differential equation of roadway floor can be expressed as follows:

$$
\begin{gathered}
D \nabla^{4} \omega=q \\
q=\frac{\partial^{2} \omega}{\partial x^{2}} \int_{-h / 2}^{h / 2} \sigma_{x} \mathrm{~d} t+2 \frac{\partial^{2} \omega}{\partial x \partial x} \int_{-h / 2}^{h / 2} \sigma_{x y} \mathrm{~d} t+\frac{\partial^{2} \omega}{\partial y^{2}} \int_{-h / 2}^{h / 2} \sigma_{y} \mathrm{~d} t \\
\sigma_{x}=\mu \sigma_{y}
\end{gathered}
$$

In the formula, $D$ refers to the bending stiffness of the floor rock; $\sigma_{x}$ means the horizontal stress of the floor; $\sigma_{y}$ means the floor normal stress of roadway strike; $\sigma_{x y}$ means the shear stress of the floor. In order to solve the critical stress in the critical state of floor flexure, the homogeneous solution of $\omega$ of floor deformation is composed of the superposition of the two-dimensional Levi solution. Then, $\omega$ can be expressed as follows:

$$
\begin{aligned}
\omega & =\sum_{m=1,2,3 \ldots}^{\infty} A_{m} \sin \left(\alpha_{m} x\right)+\sum_{n=1,2,3 \ldots}^{\infty} B_{n} \sin \left(\beta_{n} y\right), \\
A_{m} & =\frac{2\left(\alpha_{m} \tanh \alpha_{m}+2\right)}{\pi^{5} m^{5} \cosh \alpha_{m}}
\end{aligned}
$$




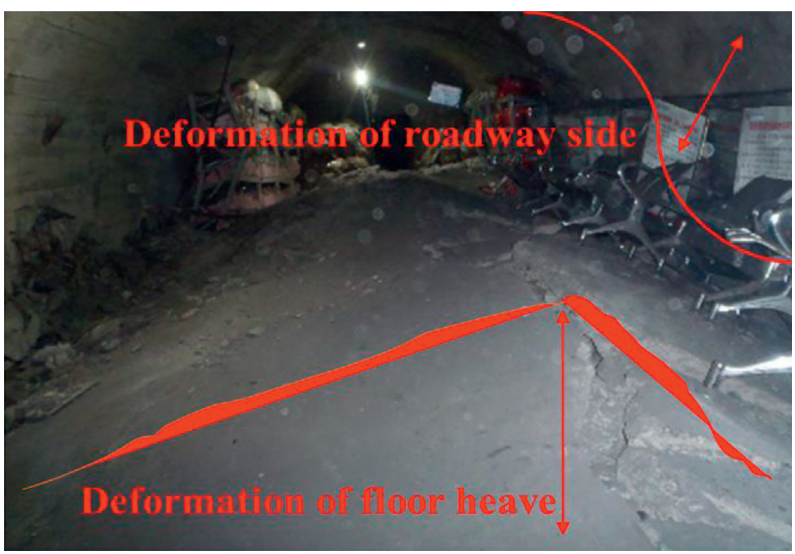

FIGURE 1: Deformation and failure of the roadway.

TABLE 1: Bursting liability of coal sample.

\begin{tabular}{lccccc}
\hline Location & $R_{\mathrm{C}}(\mathrm{MPa})$ & $K_{\mathrm{E}}$ & $W_{\mathrm{ET}}$ & DT $(\mathrm{ms})$ & Result (bursting liability) \\
\hline Coal seam & 11.3312 & 1.26 & 2.59 & 580 & Weak \\
Floor & 14 & 3.76 & 4.58 & 510 & Weak \\
\hline
\end{tabular}

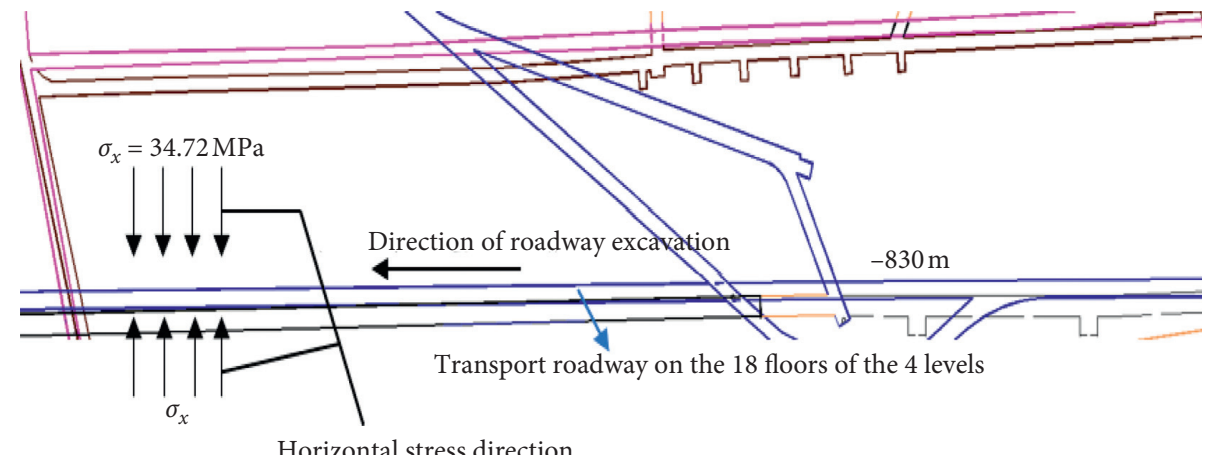

FIgURE 2: Roadway layout and horizontal stress direction.

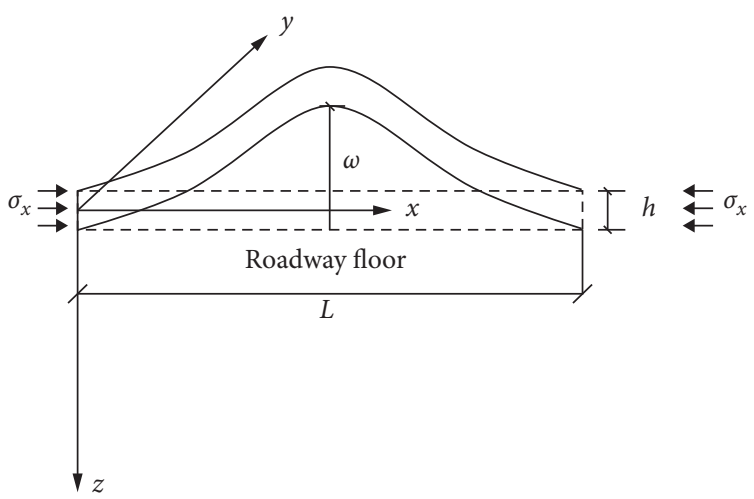

FIGURE 3: Schematic diagram of roadway floor stress analysis. 


$$
\alpha_{m}=\frac{m \pi}{L}
$$

In the formula, $A_{m}$ is undetermined coefficients, and $L$ is the transverse calculated length of floor, and $B_{m}$ is the longitudinal calculated length of the floor. Since the length $Y$ of the roadway strike is much larger than the width $X$ of the roadway floor, and the load suffered after the roadway excavation is mainly related to the $X$ direction, so the displacement, deformation, and stress of the roadway floor are only single-valued functions related to $X$. Therefore, formulas (2) and (3) can be simplified as follows:

$$
\sum_{m=1,2,3 \ldots}^{\infty} A_{m}\left(\frac{D m^{4} \pi^{4}}{L^{4}}-\frac{m^{2} \pi^{2} \sigma_{x} h}{L}\right) \sin \frac{m \pi x}{L}=0,
$$

The higher-order in the infinite series is omitted, so $m=1$ is substituted into the bending stiffness of the roadway floor. The horizontal stress balance equation under the buckling state of the floor can be obtained as follows:

$$
\frac{\pi^{4} D}{L^{4}}-\frac{\pi^{2} \sigma_{x} h}{L}=0
$$

The critical buckling stress of floor failure can be obtained by solving the equation:

$$
\sigma_{x c r}=\frac{\pi^{2} D}{h L^{3}}=\frac{\pi^{2} E b h^{2}}{12 L^{3}}
$$

In the formula, $b$ is the spacing of the supporting structure. According to the above equation, when the stress in the plastic zone of the roadway floor exceeds the critical buckling stress, the floor will fail in stability.

$$
\sigma_{x}=\sigma_{x c r}
$$

From the above equation, it can be seen that $\sigma_{x}>\sigma_{x c r}$, floor rock instability occurs. At this time, the floor will bend and deform under the action of horizontal stress, which can easily induce the rock burst of the roadway floor, thus endangering the safety of the roadway.

3.2. Analysis of Floor Energy. According to the minimum energy principle of rock mass destruction [15], the energy condition of rock burst at the floor is as follows:

$$
\begin{aligned}
& E_{0}=\mathrm{E}_{\omega}+E_{D}-E_{c}>0, \\
& E_{c}=\frac{\sigma_{c}^{2}}{2 E},
\end{aligned}
$$

In the formula, $E_{0}$ is the residual elastic energy; $E_{\omega}$ is the elastic strain energy of the floor; $E_{\mathrm{D}}$ is the energy propagated by dynamic stress waves to the surrounding roadway. When rock burst is induced by static load, $E_{\mathrm{D}}$ can be 0 ; $E_{\mathrm{c}}$ is the energy consumed by rock mass failure; $\sigma_{c}$ is the residual strength of floor rock. The following equation can be obtained:

$$
E_{0}=\frac{\sigma_{x \mathrm{cr}}^{2}-\sigma_{c}^{2}}{2 E}=\frac{\pi^{4} E^{2} b^{2} h^{4}}{288 L^{6}}-\frac{\sigma_{c}^{2}}{2 E},
$$

According to equation (10), the residual elastic energy of floor soft rock is related to the ultimate horizontal stress of floor rock mass, the elastic modulus, the spacing of the supporting structure, the residual strength, the floor width of the roadway, and the thickness of soft rock layer. In Figure 4, the elastic modulus is $12.5 \mathrm{GPa}$, the residual strength is $12 \mathrm{MPa}$, and the ultimate stress of the floor ranges from $25 \mathrm{MPa}$ to $110 \mathrm{MPa}$. With the increase of the ultimate horizontal stress, the elastic energy of floor rock mass increases with the speed of the second power of horizontal stress. In Figure 5, the elastic modulus is $12.5 \mathrm{GPa}$; the floor width of the roadway is $4.5 \mathrm{~m}$; the range of the thickness of the weak rock layer is 0 to $5 \mathrm{~m}$; the residual strength of floor rock mass is $12 \mathrm{MPa}$. The spacing between supporting structures is $0.8 \mathrm{~m}$. As the thickness of soft strata increases, the floor elastic energy density also increases. Compared with horizontal stress, the thickness of weak rock has a more severe influence on the floor's elastic energy. When the thickness of weak rock is greater than $2 \mathrm{~m}$, the floor elastic energy is positively correlated with the fourth power of the thickness of soft rock.

\section{Floor Pressure Relief and Stress Barrier Technology}

4.1. Mechanism of the Pressure Relief and Stress Barrier Technique for Rock Burst Prevention. The analysis of the thickness, ultimate stress, and energy evolution of the weak rock layer at the floor of the roadway [16] shows that the main cause of the rock burst at the floor of the roadway is the high horizontal stress at the floor and the high energy accumulated by the thicker weak rock near the critical surface of the floor. Therefore, it is necessary to reduce the horizontal stress and the deformation of the floor, so as to prevent the rock burst of the floor of the roadway and increase the upper limit of energy storage of the floor. According to the law of stress and elastic energy accumulation and evolution of the roadway floor, a large diameter pressure relief and stress barrier control technique is proposed.

As shown in Figure 6, the pressure relief and stress barrier control technique consists of three parts: pressure relief, grouting, and pile formation. At first, large diameter boreholes are carried out to relieve pressure at the floor corner. After the pressure has been removed, steel tubes of a specified size are placed in the borehole. Secondly, grouting is carried out inside the steel tubes, and the grout enters the rock mass cracks through the reserved holes of the steel tubes. Grouting reduces the deformation of the surrounding rock on the one hand and bonds the steel tube to the surrounding rock on the other, thus forming a community of forces. Thirdly, after the grouting is completed, the steel tube is filled with self-compacting concrete to form a concrete-filled steel tube pile (hereinafter referred to as CFST pile). CFST pile can strongly cut the horizontal stress and prevent the floor from rock burst and sliding. In addition to [17], the mechanical mechanism similar to the bolt will also be studied. 


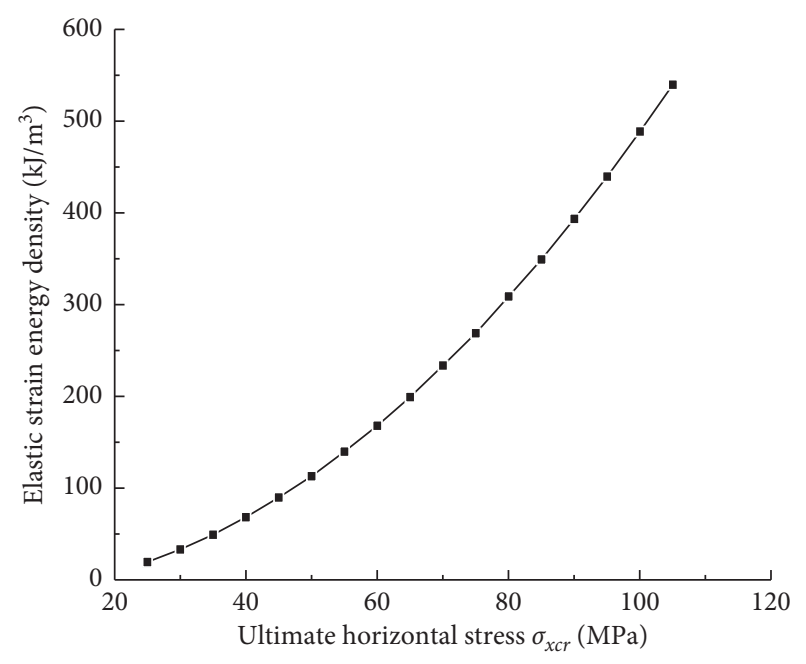

Figure 4: Curves of the elastic strain energy density for different values of horizontal stress.

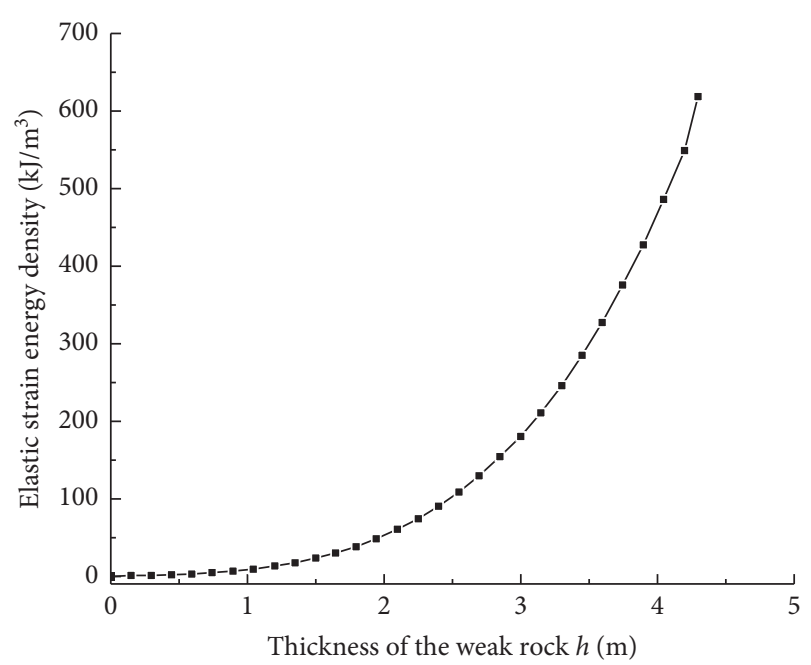

Figure 5: Curves of the elastic strain energy density for different values of weak rock thickness.

4.2. CFST Pile Stress Barrier Design Parameters. Since one end of the foundation pile is embedded in the hard rock, the far end can be regarded as a fixed constraint. The surrounding rock of the bottom plate can restrain its rotation angle, so the proximal end can be simplified as sliding support. The structural calculation model of the CFST pile is shown in Figure 7.

As the CFST is encapsulated within the grouting body, it can exhibit good ductility under the action of the surrounding pressure. Considering the strength of CFST after buckling, the barrier stress calculated by the plastic design method can better reflect its actual stress state. According to the plastic design theory of structures [18], some local sections of structures will appear plastic hinges when they reach the ultimate bending moment. When enough plastic hinges appear, the original structure will lose its loadbearing capacity, at which point the ultimate load corresponding to the steel pipe concrete is both the ultimate barrier stress $\sigma^{*}$. According to the constraint stress condition of the CFST pile, the place of the plastic hinge is shown in Figure 8.

According to the virtual work principle, the virtual work done by the external force is equal to the virtual work done by the internal force on the corresponding virtual deformation. Therefore, if the virtual displacement at the constraint position is $\theta$, it can be known from the geometric relationship that the virtual displacement at the mid-span is $2 \theta$, so the virtual work of the external force is as follows:

$$
W_{e}=q \times \frac{h}{2} \times \frac{h \theta}{2}=\frac{1}{4} q h^{2} \theta .
$$

The virtual work of the internal force is as follows:

$$
W_{i}=M_{u} \times \theta+M_{u} \times 2 \theta+M_{u} \times \theta=4 M_{u} \theta .
$$

Let $W_{\mathrm{e}}=W_{\mathrm{i}}$, then the relation between ultimate load and barrier stress is as follows:

$$
\sigma^{*}=\frac{16 M_{u}}{h^{2}}
$$

Since steel tubes are filled with C40 self-compacting concrete, the flexural bearing capacity of CFST members can be simplified into the following equation:

$$
M_{u}=\frac{\pi(-0.483 \theta+1.926 \sqrt{\theta}) r_{0}^{3} f_{s c}}{4},
$$

where $\theta=a_{s c} f \mid f_{c}$ is the collar coefficient of CFST, $\theta=a_{s c} f / f_{c}$ is the steel content ratio, $r_{0}$ is the radius of steel tube, and $f_{s c}$ is the design value of compressive strength of CFST. By combining (12) and (13), the ultimate barrier stress of CFST can be calculated as follows:

$$
\sigma^{*}=\frac{4 \pi(-0.483 \theta+1.926 \sqrt{\theta}) r_{0}^{3} f_{s c}}{b h^{2}} .
$$

After grouting, the stress in the plastic zone of the surrounding rock of the floor is $32.15 \mathrm{MPa}$, and the critical pressure of the floor is $28.35 \mathrm{MPa}$. Since the stress in the plastic zone is greater than the critical buckling stress, the floor will be destabilized. As shown in Figure 8, the ultimate barrier stress gradually increases with the increase of the radius of CFST. When the pile diameter is below $80 \mathrm{~mm}$, the ultimate barrier stress shows a similar linear growth trend with the equivalent radius of the CFST pile, and the growth range of ultimate reaction force is not visible. This is because, under the action of horizontal stress, the stress state of the CFST pile is mainly bending, so the increase of pile diameter plays a decisive role in the bending stiffness of the floor. CFST pile spacing also has a significant effect on the increase of barrier stress. When the pile spacing is greater than $1200 \mathrm{~mm}$, the barrier stress provided by the CFST pile is less than $1.5 \mathrm{MPa}$. When the pile spacing $b$ is less than $600 \mathrm{~mm}$, the ultimate barrier stress increases markedly. Under the same pile diameter, the maximum difference of the barrier stress between $300 \mathrm{~mm}$ and $600 \mathrm{~mm}$ pile spacing can be $4 \mathrm{MPa}$. On the one hand, this is because the barrier stress is 


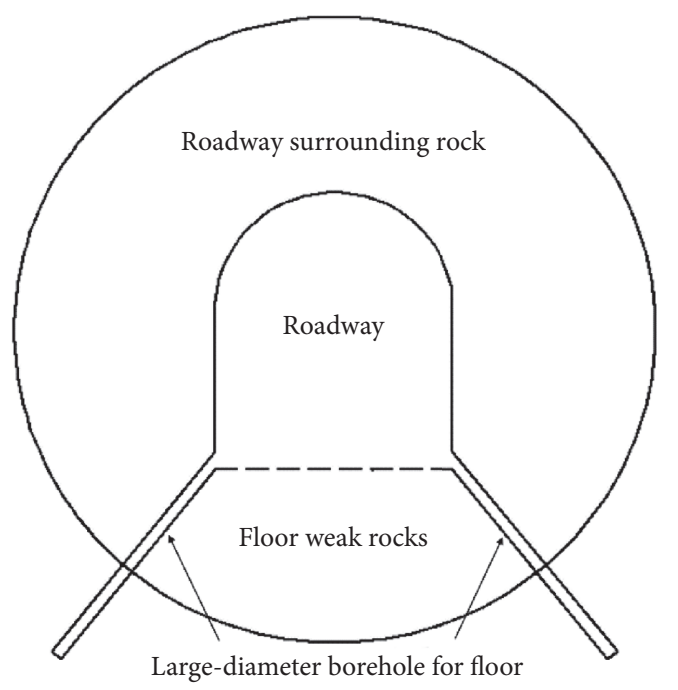

(a)

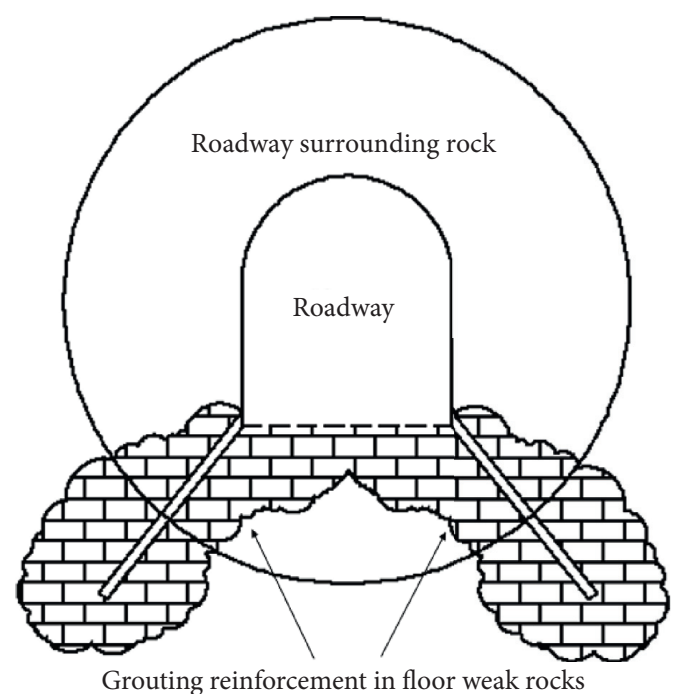

(b)

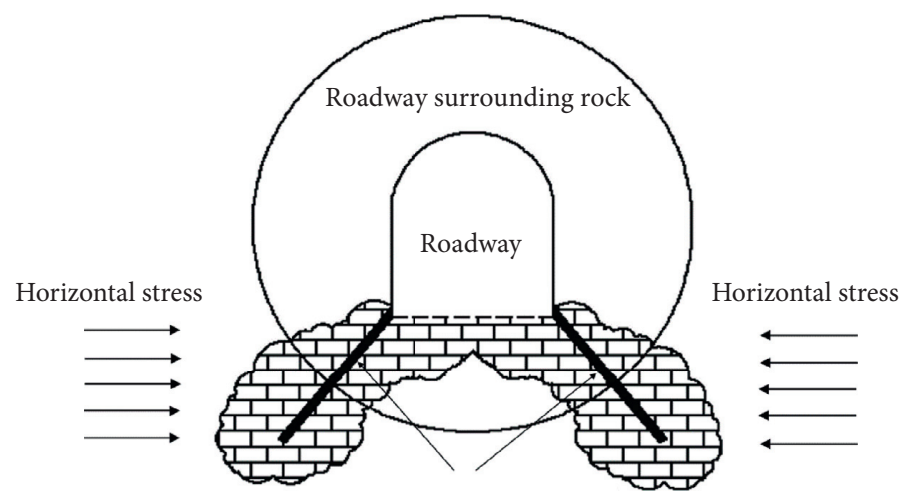

Concrete-filled steel tube pile

(c)

FIgURE 6: Pressure relief and stress resistance technology in roadway floor. (a) The large-diameter borehole pressure relief. (b) Grouting reinforcement technique. (c) Floor corner pile stress resistance.

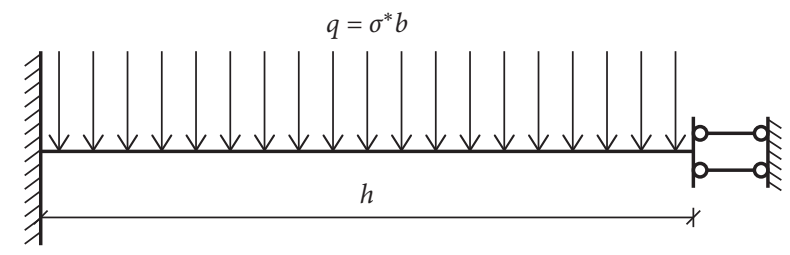

Figure 7: Internal force calculation model of floor corner pile.

inversely proportional to the pile spacing; on the other hand, because the pile spacing is too huge, the stress area shared by each pile is large, which leads to the insignificant barrier effect of stress.

\section{Numerical Analysis of Roadway Floor Rock Burst Prevention and Control}

In order to study the supporting effect of roadway pressure relief and stress barrier technology (Figure 9), a numerical model was established in FLAC3D software according to the engineering geological conditions of roadway in a four-level working face. The numerical model simulates the influence of large diameter borehole pressure relief and concrete-filled steel tube stress barrier technology on the evolution law of stress and elastic strain energy of roadway floor and analyzes the floor rock burst prevention effect of roadway floor.

According to the influence range of stress, the size of the value is $200 \mathrm{~m} \times 120 \mathrm{~m} \times 100 \mathrm{~m}$, as shown in Figure 10. The displacement in the direction of $X Y Z$ is fixed at the bottom of the model, and the normal displacement on all surfaces is constrained around. The upper surface of the model is a free surface and the vertical stress $\sigma_{z}$ corresponding to the thickness of the overburden is applied. According to the geological profile of the place of the roadway, the surrounding rock of the roadway can be simplified as fine sandstone, mudstone, and medium sandstone. The rock above the roadway surrounding rock can be regarded as overlying rock and the rock below the roadway surrounding rock is medium sandstone. The mechanical parameters of rock mass were obtained through laboratory tests. The mechanical parameters of the surrounding rock are shown in Table 2. 


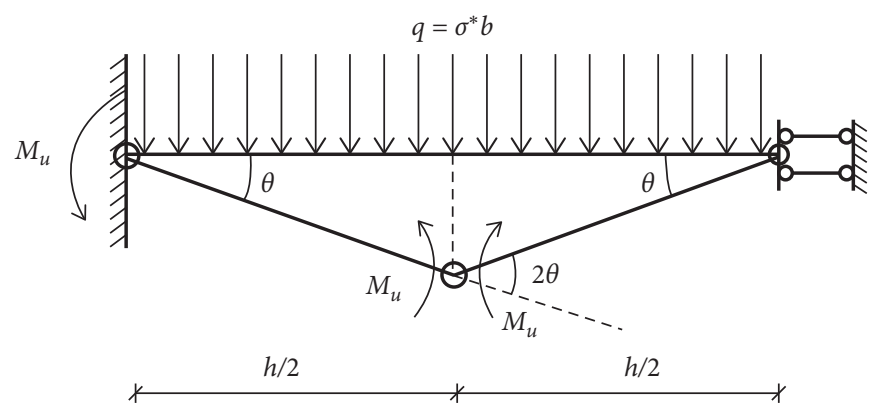

Figure 8: Calculation model for the ultimate load of CFST pile.

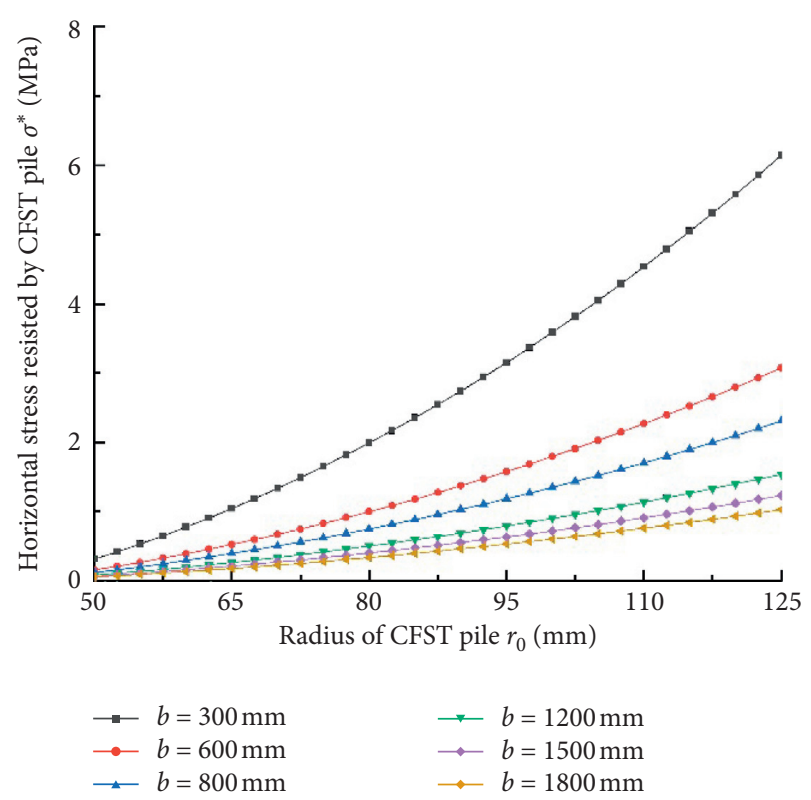

FIGURE 9: Influence of supporting parameters on stress resistance.

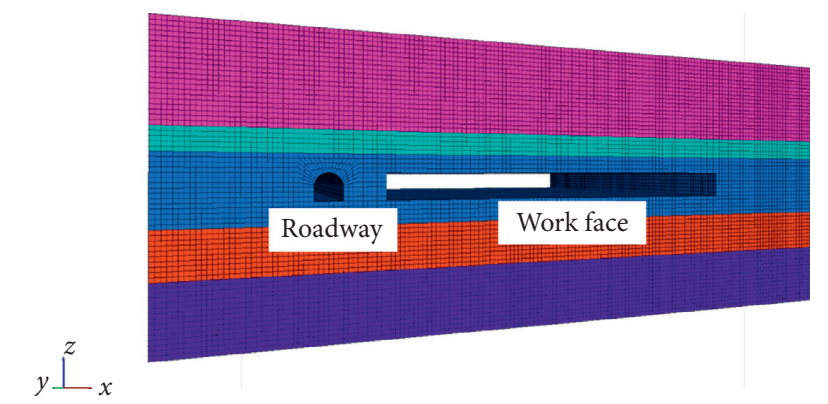

FIGURE 10: Influence of supporting parameters on stress resistance.

On the assumption that floor rock mass is isotropic, the Mohr-Coulomb model is adopted as the constitutive model. Because CFST pile has larger supporting stiffness and better flexural shear performance, CFST pile simulation using the pile structure unit $[19,20]$, and open the bolt characteristics, can better achieve its common bearing characteristics with the surrounding rock. According to the calculation above, CFST pile section diameter is $200 \mathrm{~mm}$, and pile spacing is $600 \mathrm{~mm}$. U-shaped steel support in the roadway is simulated by shell element, with an interval of $800 \mathrm{~mm}$. The spatial layout of structural units is shown in Figure 11.

5.1. Analysis of Plastic Zone of Floor Coal and Rock. After excavation, the plastic zone begins to diffuse outwards from the surrounding rock, and the volume of the plastic zone in the surrounding rock increases continuously. Figure 12 is the elastoplastic separation layout in the numerical model of the roadway. The elastic zone, shear failure zone, and shear and tensile failure zone in the figure are shown as legends.

As can be seen from Figure 12, when the roadway floor was not supported, the floor first entered the plastic zone and continued to expand to the two sides, and the volume of the plastic zone showed a characteristic of constant increase. The rapid expansion of plasticity is frequently accompanied by the occurrence of rock burst. Due to the volume limitation of the plastic zone, the rock burst starts from the floor and the two sides. When the floor is supported by a large diameter borehole and pile foundation of the floor, the plastic zone is definitely transferred to the deep rock mass, the volume of the plastic zone is obviously smaller than that of the relatively unsupported rock mass, and the rock burst risk of the floor and two sides is weakened.

5.2. Horizontal Stress Analysis of Floor. Figure 13 shows the horizontal stress evolution curve of the floor after roadway excavation. A positive distance to the driving face means that behind the driving face, excavations have been made. A negative distance to the heading face indicates that it in front of the heading face and has not yet been excavated. It can be seen that the floor rock mass is basically in the original rock stress state before excavation of the tunnelling roadway. After roadway excavation, the horizontal influence concentrates on the floor area. It can be seen that the floor rock mass is basically in the original rock stress state before excavation of the tunnelling roadway. After roadway excavation, the horizontal influence concentrates on the floor area. Before the floor is not supported, the high horizontal stress concentration area of the floor is mainly located in the area $2 \mathrm{~m}$ to $5 \mathrm{~m}$ behind the heading face when the heading face advances, and the stress concentration coefficient is 2.4 to 1.6. With the increase of the distance from the heading face, the influence of the floor coal thickness on the floor coal stress is gradually weakened, and the stress concentration tends to 1.4. When the control measures are taken on the 
TABLE 2: Mechanical parameters for surrounding rock and coal.

\begin{tabular}{|c|c|c|c|c|c|}
\hline Rock & $\begin{array}{c}\text { Density } \\
\left(\mathrm{g} \cdot \mathrm{cm}^{-3}\right)\end{array}$ & $\begin{array}{c}\text { Cohesion } \\
(\mathrm{MPa})\end{array}$ & $\begin{array}{c}\text { Internal friction angle }(\varphi) \\
\left({ }^{\circ}\right)\end{array}$ & $\begin{array}{l}\text { Elasticity modulus }(E) \\
(\mathrm{MPa})\end{array}$ & Poisson ratio $(\mu)$ \\
\hline Overlying rock & 2.61 & 20 & 35 & 7000 & 0.30 \\
\hline Fine sandstone & 2.75 & 8.9 & 33.4 & 4560 & 0.19 \\
\hline Mudstones & 2.51 & 0.97 & 26 & 4560 & 0.31 \\
\hline $\begin{array}{l}\text { Medium } \\
\text { sandstone }\end{array}$ & 2.48 & 4.7 & 36 & 4800 & 0.27 \\
\hline Coal & 2.61 & 20 & 38 & 8600 & 0.25 \\
\hline
\end{tabular}

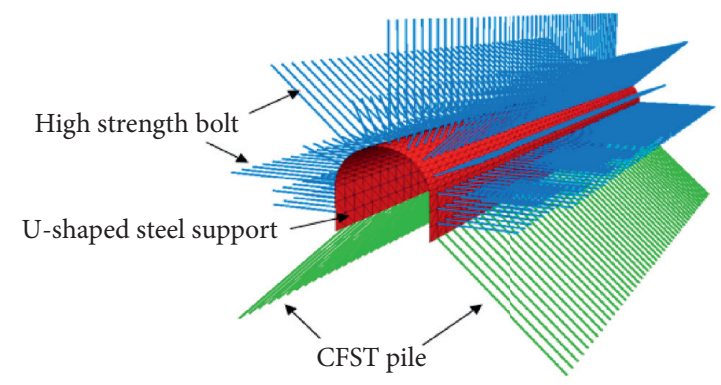

Figure 11: Structural element model.

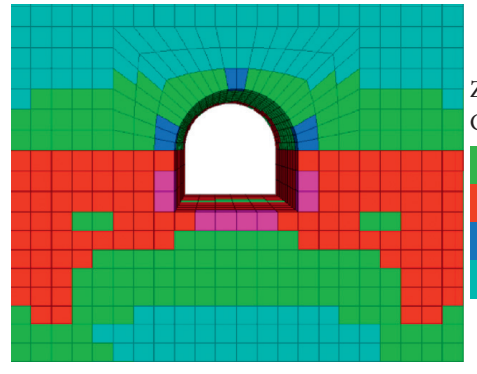

(a)

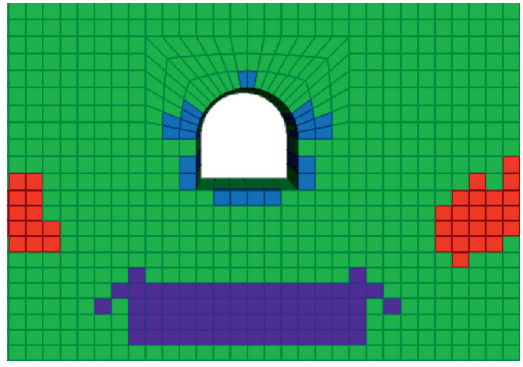

Zone

Colorby: state-average

None

Shear- $n$

Shear- $n$ shear- $p$

Shear- $p$

Shear- $p$ tension- $p$

Tension- $n$ shear- $p$ tension $-p$

Figure 12: Distribution of elastic-plastic floor zone. (a) Floor without support. (b) Floor for pressure relief and support.

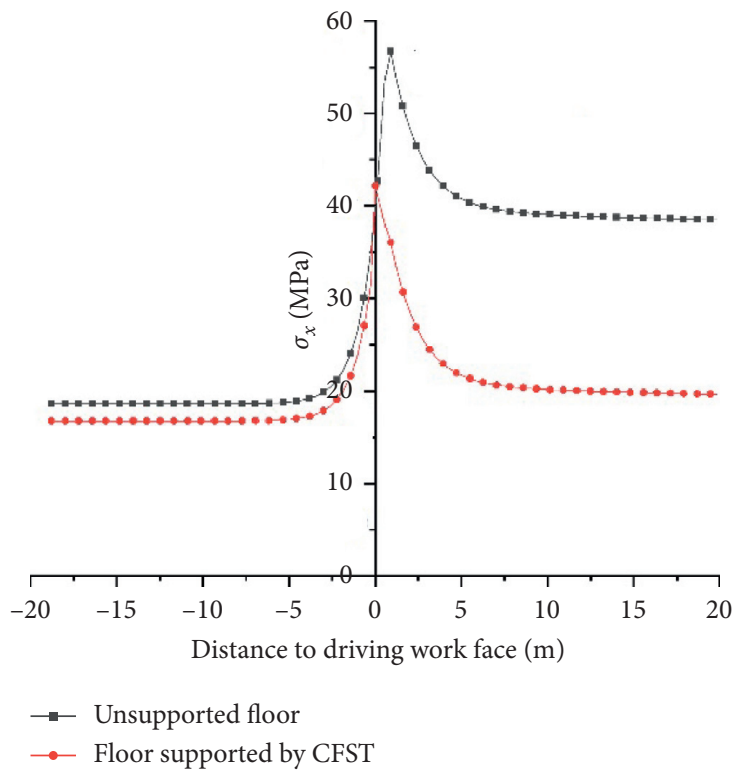

FIGURE 13: Horizontal stress evolution curve before and after driving working face. 
floor, the stress concentration of the floor decreases obviously, except that the horizontal stress is slightly concentrated near the working face, and the distance from the working face increases, the horizontal stress transfers to the depths, and the floor stress is close to the original rock stress state.

Figure 14 shows the horizontal stress state of the floor and surrounding rock of the roadway section. When the floor pressure was relieved and supported by the CFST pile, the horizontal stress of the roadway floor decreased from $40 \mathrm{MPa}$ to $25 \mathrm{MPa}$, and the stress concentration decreased significantly. The horizontal stress of the floor after the support was less than the ultimate stress, and no instability and large deformation occurred. With the increase of the distance from the roadway section, the horizontal stress of the floor surrounding rock decreases somewhat, but the decreasing degree decreases somewhat. This indicates that the CFST pile can effectively block the compression of stress in the plastic zone to the floor surrounding rock and transfer it to the deep rock mass, and its isolation effect gradually decreases with the distance from the roadway section.

5.3. Analysis of Elastic Energy of Floor Surrounding Rock. Based on the generalized Hooke's theorem, the calculation formula of the elastic strain energy $E_{r}$ stored in the coal and rock mass under three-direction stress is as follows:

$$
E_{r}=\frac{\sigma_{1}^{2}+\sigma_{2}^{2}+\sigma_{3}^{2}-2 \mu\left(\sigma_{1} \sigma_{2}+\sigma_{1} \sigma_{2}+\sigma_{1} \sigma_{2}\right)}{2 E} .
$$

In the formula, $E$ is the elastic modulus; $\mu$ is Poisson's ratio; $\sigma_{1}$ is the maximum principal stress; $\sigma_{2}$ is the intermediate principal stress. $\sigma_{3}$ is the minimum principal stress. The calculation command of elastic strain energy density distribution of floor rock mass under horizontal stress was written with FISH language. The calculated evolution curve of the elastic strain energy density of floor rock mass after roadway excavation is shown in Figure 15.

As can be seen from Figure 15, when the floor was not treated, the elastic strain energy density of the floor first decreased and then increased with the increase of the distance from the floor. The elastic strain energy density of the floor is large when the distance from the heading face is 0 to $3 \mathrm{~m}$, which is easy to induce floor rock burst. When the distance from the roadway floor is greater than $5 \mathrm{~m}$, the elastic strain energy density of the roadway floor gradually decreases with the increase of the tunnelling working face. The elastic strain energy density of the roadway floor fluctuates near the heading face when the floor is drilled to relieve pressure and support and decreases obviously when the floor is not treated. Compared with Figure 14, it can be seen that the elastic strain energy density value of the roadway floor is mainly controlled by the horizontal principal stress, which verifies that the rock burst of the roadway floor is mainly the result of the action of horizontal stress.

Figure 16 is the horizontal stress cloud diagram of floor support. It can be seen from the figure that the horizontal stress of the floor surrounding rock decreases to a certain extent after CFST support. The maximum horizontal stress

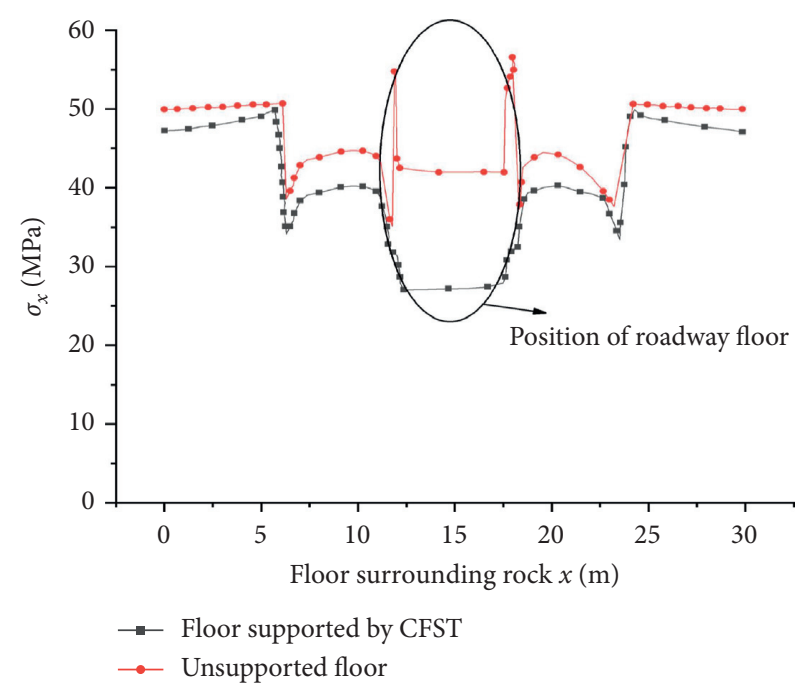

Figure 14: Horizontal stress of roadway floor cross section.

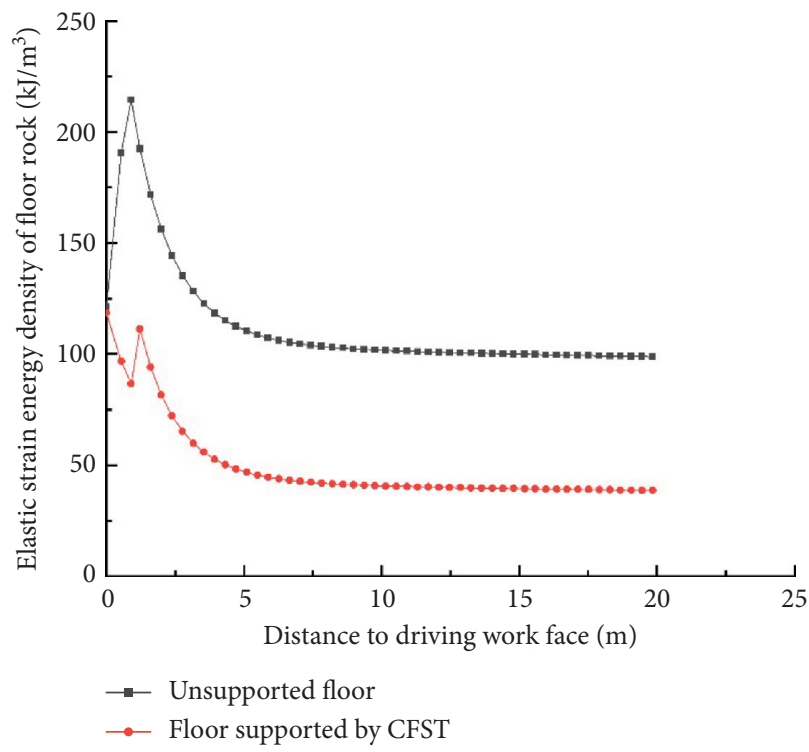

FIGURE 15: Floor energy evolution curve before and after driving working face.

of the surrounding rock near the floor decreases from 32.5 MPa to $22.5 \mathrm{MPa}$, and the stress near the free surface of the floor decreases from 20.8 MPa to $10 \mathrm{MPa}$. The decrease of horizontal stress also changes the energy density of surrounding rock. The elastic energy cloud diagram of the floor surrounding rock is shown in Figure 17. In Figure 17, red, yellow, green, and blue successively indicate that the elastic energy accumulation degree gradually decreases from high to low. As can be seen from Figure 17(b), after excavation of the tunnelling roadway, the elastic energy is mainly concentrated in the bottom angles of the two sides of the roadway and the place of floor strata, which can easily lead to rock burst on the floor. When the floor is depressurized and supported, the bottom angles of the two sides and the floor elastic energy decrease sharply and significantly, and the 


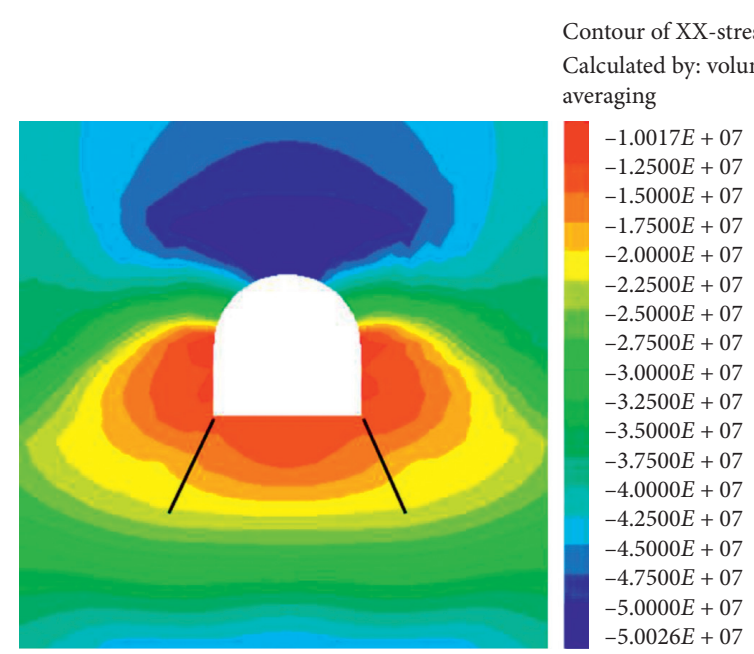

(a)

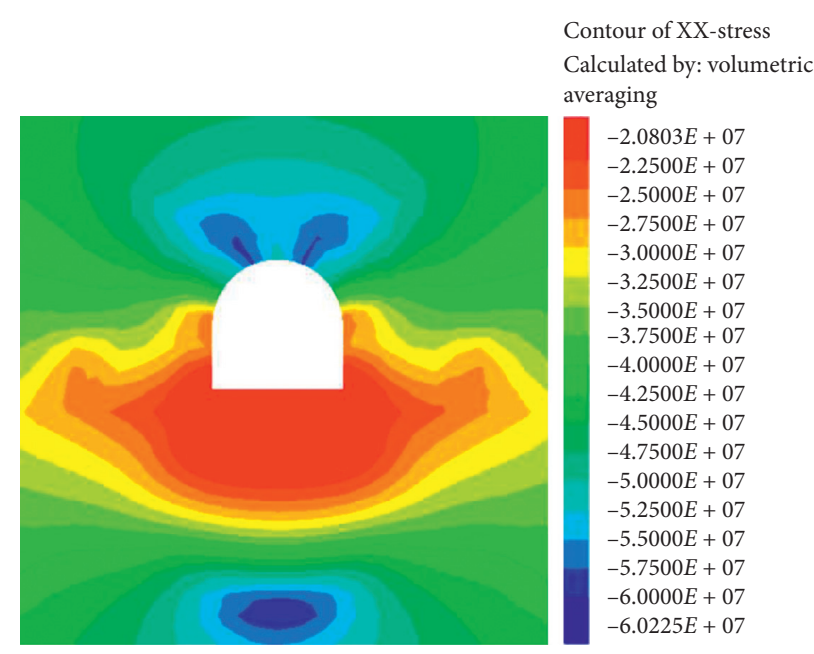

(b)

FIGURE 16: Horizontal stress cloud diagram of floor rock. (a) Floor for pressure relief and support (b) Floor without support.

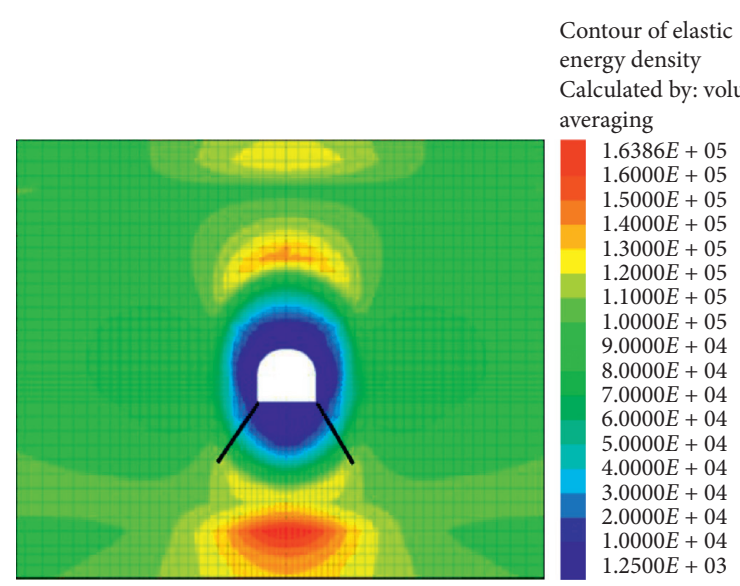

(a)

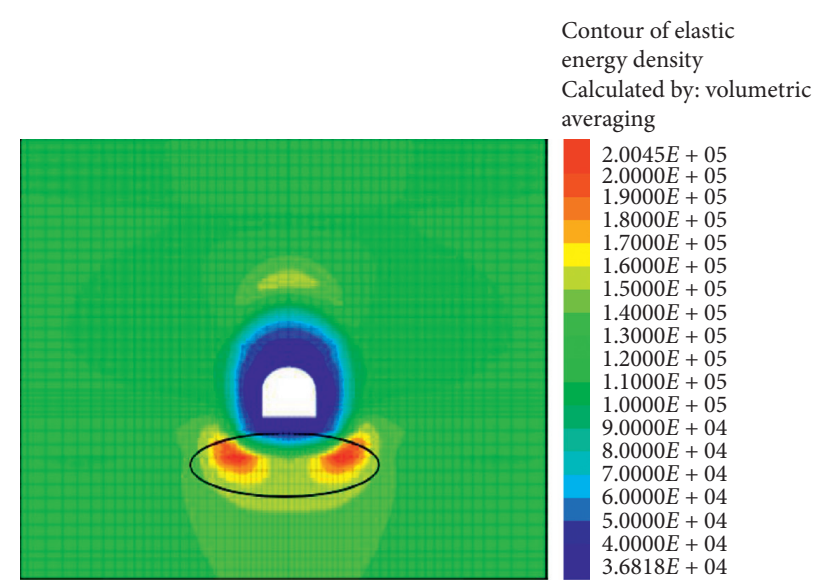

(b)

FIgURE 17: Elastic energy cloud diagram of roadway rock. (a) Floor for pressure relief and support (b) Floor without support.

high elastic accumulation area transfers to the deep rock mass, and the tendency of floor rock burst induced decreases significantly. In fact, although the foundation of the floor pile is a rigid supporting structure, it increases the energy storage limit of the floor, which means that the energy limit before the occurrence of rock burst is increased. Only a small amount of dynamic load generated by roof structure failure is transmitted to the floor, so rock burst is more difficult to occur on the floor.

\section{Engineering Case Analysis}

The site test location is selected as the track tunnelling roadway on the 18th floor in the south of the fourth horizontal of Xing'an mine. The floor pressure relief borehole and floor pile support are arranged. The spacing of boreholes is $400 \mathrm{~mm}$, the diameter of boreholes is $200 \mathrm{~mm}$, the depth of boreholes is $10 \mathrm{~m}$, and the CFST pile length is $9 \mathrm{~m}$. The layout of the floor is shown in Figure 18.

Planar microseismic distribution events of surrounding rock are shown in Figure 19. After the floor is supported by the CFST pile, the number of microseismic events near the roadway surrounding rock decreases, but the number of microseismic events decreases most at the floor. Therefore, in order to study the effectiveness of large diameter boreholes and CFST pile support technology in controlling floor rock burst, the three-dimensional distribution of floor microseismic events at the place of the floor are shown in Figure 20. In the unsupported floor area, there are many stress concentration phenomena in the floor, and due to the continuous development of floor cracks, a large number of microseismic events occur in the surrounding rock of the microseismic floor. Under the action of high horizontal stress, the surrounding rock of the floor is damaged, and the accumulated elastic energy is released suddenly. Thus, many 


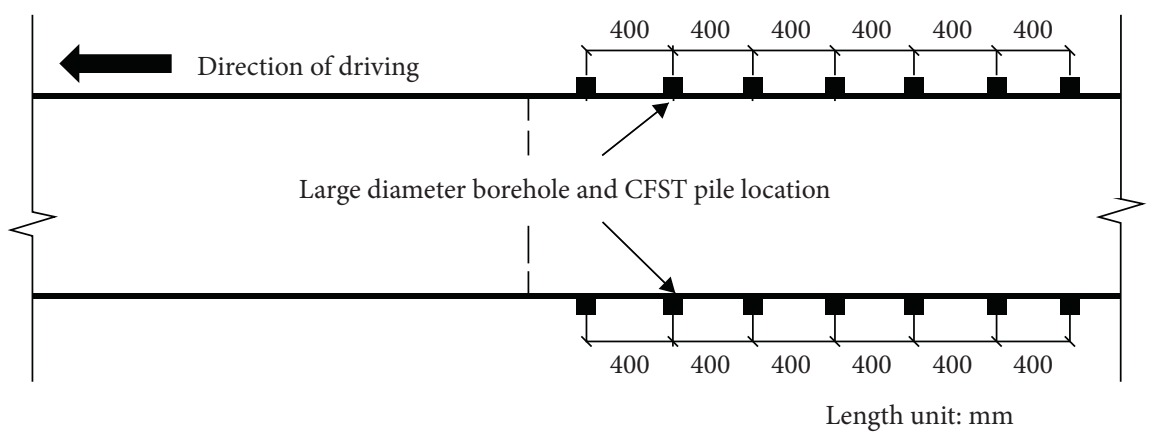

FIGURE 18: Large diameter borehole and CFST pile layout.

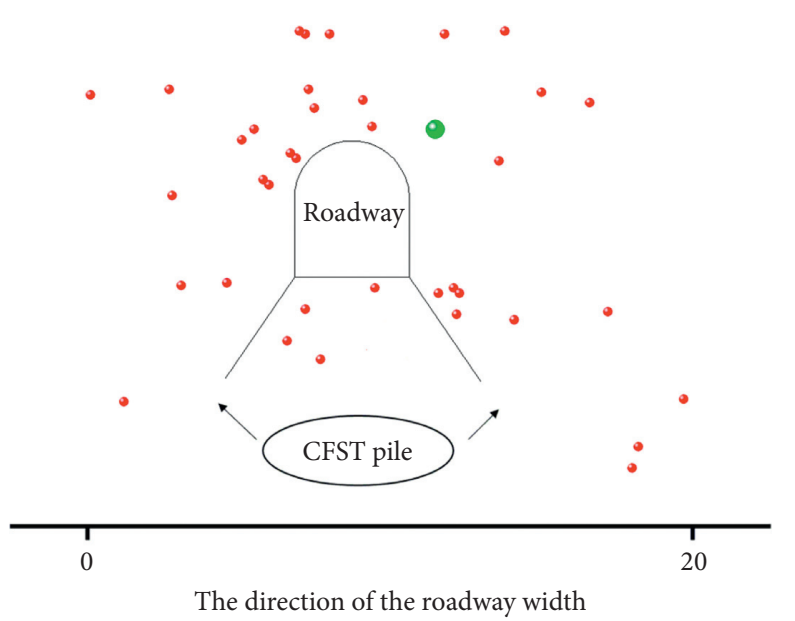

\section{Energy}

- $1 \times 10^{2} \sim 9 \times 10^{2}$

$1 \times 10^{3} \sim 9 \times 10^{3}$

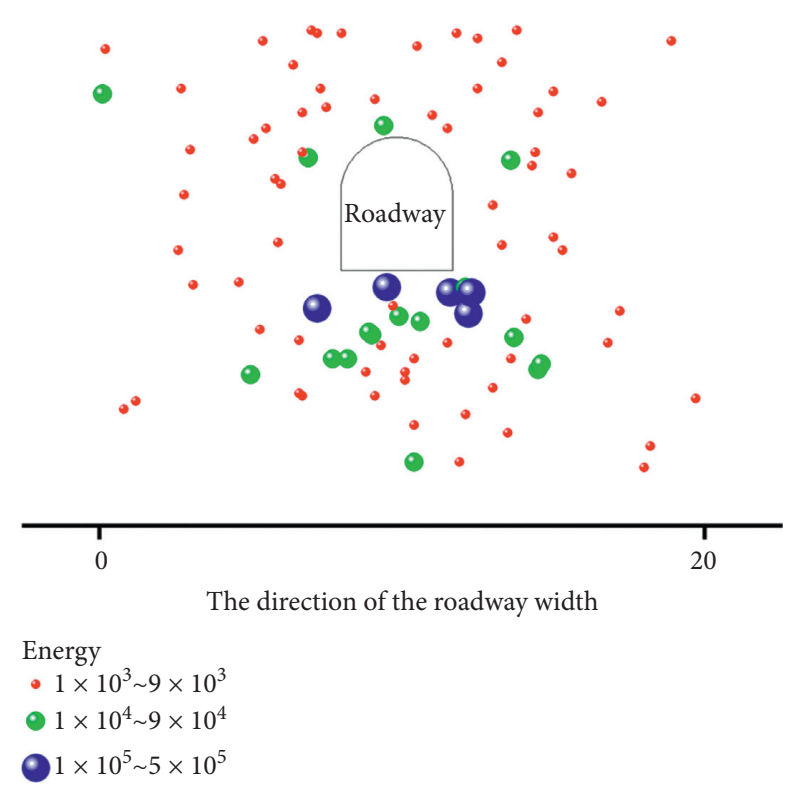

(a)

(b)

Figure 19: Microseismic events of roadway rock. (a) Floor for pressure relief and support. (b) Floor without support.

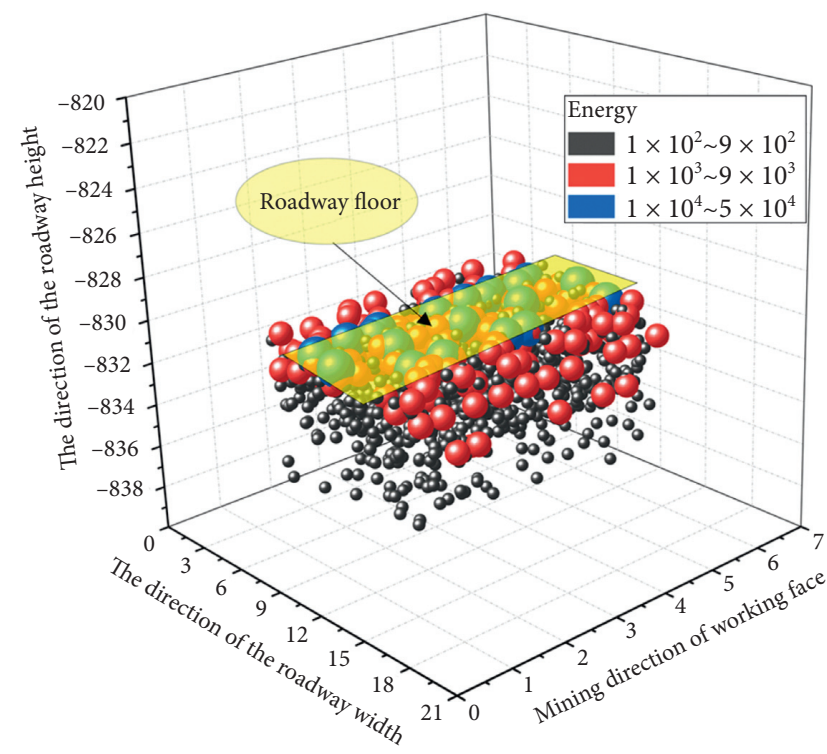

(a)

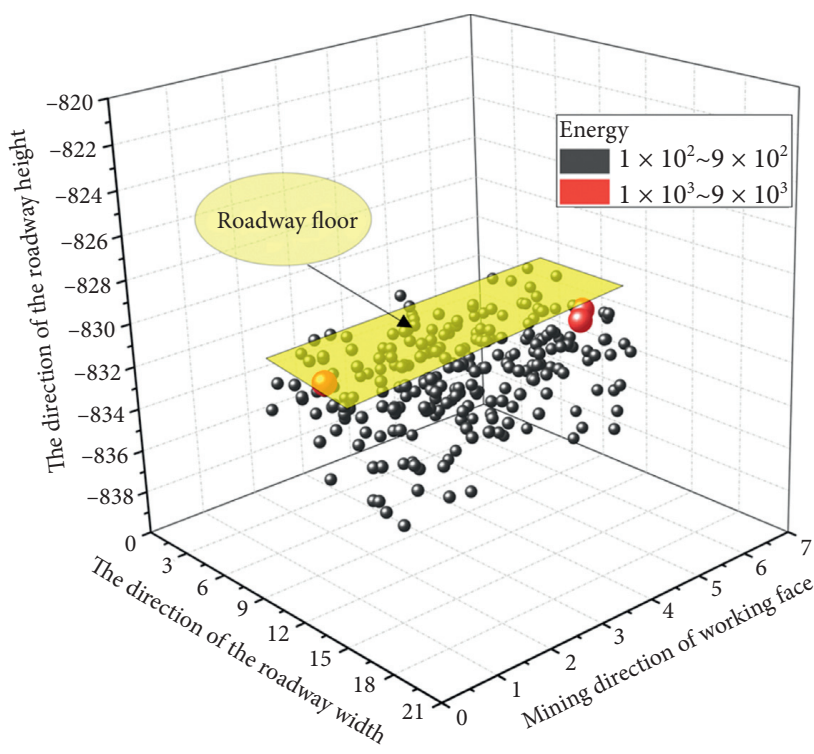

(b)

Figure 20: Three-dimensional microseismic events of the floor. (a) Floor without support. (b) Floor for pressure relief and support. 


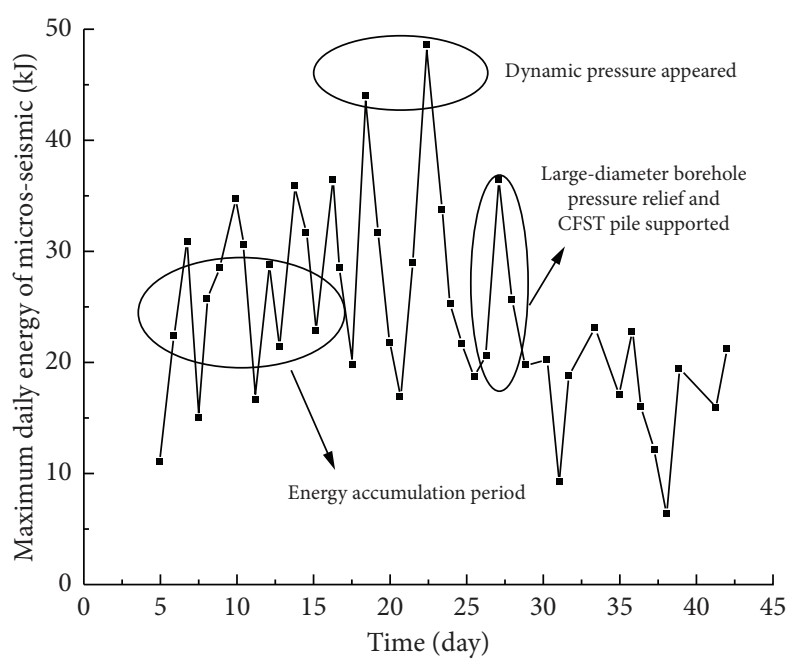

Figure 21: Statistical analysis of microseismic energy and frequency.

high energy microseismic events occur. When the roadway floor is supported by the CFST pile, the ability of the floor surrounding rock to resist horizontal stress is significantly enhanced, and the energy storage limit is significantly increased. At the same time, CFST support and floor grouting significantly inhibit the development of cracks, and the broken degree of floor surrounding rock is low. Compared with the unsupported areas, the floor microseismic events show the characteristics of low frequency and sublow energy.

The microseismic energy and frequency distribution recorded by the mine microseismic monitoring system during the roadway excavation are shown in Figure 21. According to the analysis in Figure 21, in the process of tunnelling, there was a process of energy accumulation before the rock burst of roadway floor appeared. The large diameter borehole pressure relief is carried out on the floor, which destroys the integrity of the floor strata and releases a lot of stress. The horizontal stress transfer is cut off through the floor pile foundation support, and the roadway rock burst danger alarm is relieved. After the large-diameter pressure relief measure was adopted in the roadway, $220 \mathrm{~m}$ of roadway was tunnelled safely except for the small deformation of the roadway floor. The field test results show that the method of large diameter pressure relief and CFST pile support can effectively realize the prevention and control of roadway floor rock burst.

\section{Conclusions}

Based on the energy principle and plate deflection theory, a mechanical model of roadway floor rock burst was established, and the stress and energy criteria of roadway floor rock burst rock burst were deduced. When the roadway floor width, floor rock stiffness, rock elastic modulus, and Poisson's ratio are constant, the horizontal stress of the roadway floor is the main cause of floor rock burst.

Floor rock is the power source of floor rock burst. The effective means to prevent and control floor rock burst are to take pressure relief measures to release floor stress and adopt support means to cut off the stress transfer path to prevent and control large deformation of floor, so as to reduce the risk of floor rock burst.

Based on the comprehensive analysis of the rock burst mechanism of the floor of the tunnelling roadway, the methods of pressure relief by large diameter borehole and CFST pile floor support are put forward. Numerical simulation was used to analyze the distribution of plastic zone, horizontal stress, and elastic strain energy in surrounding rock of floor after treatment, and the effectiveness of the method was verified.

The field microseismic monitoring shows that there is a process of energy accumulation before the rock burst of the roadway floor, which can be used for the discrimination and early warning of rock burst. After the large-diameter floor drilling pressure relief and CFST pile treatment of the floor, the rock burst risk of roadway floor is removed, which ensures the roadway safety and efficient tunnelling and can provide a reference for the floor rock burst prevention and control of roadway in similar coal mines.

\section{Data Availability}

The data used to support the findings of this study are available from the corresponding author upon request.

\section{Conflicts of Interest}

The authors declare that they have no conflicts of interest.

\section{Acknowledgments}

This study was financially supported by the State Key Project of Research and Development Plan of China (2017YFC0804204) and the National Natural Science Foundation of China (51974315).

\section{References}

[1] M. Christopher and G. Michael, "Pillar design and coal burst experience in Utah Book Cliffs longwall operations," 
International Journal of Mining Science and Technology, vol. 31, no. 1, pp. 33-41, 2021.

[2] P. Gangsar and R. Tiwari, "Diagnostics of mechanical and electrical faults in induction motors using wavelet-based features of vibration and current through support vector machine algorithms for various operating conditions," Journal of the Brazilian Society of Mechanical Sciences and Engineering, vol. 41, no. 2, 2019.

[3] Y. Minami, D. Apel, and H. Xu, "A principal component analysis/fuzzy comprehensive evaluation for rockburst potential in kimberlite," Pure and Applied Geophysics, vol. 175, no. 6, pp. 2141-2151, 2018.

[4] Q. Qi, I. Pany, L. Shu, and H. Li, “Theoretical and technical framework of multi-scale and multi-source prevention and control of coal and rock dynamic disasters in deep mining," Journal of China Coal Society, vol. 43, no. 7, pp. 1801-1810, 2018.

[5] S. Zhao, L. Li, B. Wu, and Z. Ji, "Theory and application of deep hole floor break blasting in floor rock burst coal mine," Journal of Mining and Safety Engineering, vol. 33, no. 4, pp. 636-642, 2016.

[6] X. Xu, L. Dou, J. Liu et al., "Controlling function of closed compressible support structure on floor burst," Journal of Mining and Safety Engineering, vol. 31, no. 5, pp. 745-749, 2014.

[7] L. Jiang, P. Kong, P. Zhang et al., "Dynamic analysis of the rock burst potential of a longwall panel intersecting with a fault," Rock Mechanics and Rock Engineering, vol. 53, no. 4, pp. 1737-1754, 2019.

[8] T. Lijun, "The pressure changing area imbalance theory of "Three Hard" coal seam and its application," Chinese Journal of Underground Space and Engineering, vol. 10, no. 5, pp. 1192-1197, 2014.

[9] J. Liu, O. A. Zhenhua, Q. Qi et al., "Rigid-lexibility inte-grated energy absorption support technology applied in deep mine with pressure," Coal Science and Technology, vol. 41, no. 6, pp. 17-20, 2013.

[10] Y. Pan, Y. Xiao, and L. Guozhen, "Research and application of hydraulic support for tunnel anti scour," Journal of China Coal Society, vol. 45, no. 5, pp. 90-99, 2020.

[11] J. Yao, Z. Xu, J. Wang, and L. Wang, "Experimental study on rock burst control with bolt-aluminum foam combined support," Rock and Soil Mechanics, vol. 42, no. 3, pp. 620-626, 2021.

[12] H. Wang, D. Deng, Y. Jiang, R. Shi, H. Zhou, and S. Cui, "Study on ultimate bearing capacity of U-shaped steel support in mine roadway under rock burst," Journal of Mining Science, vol. 6, no. 2, pp. 176-187, 201.

[13] J. G. Lawomir and K. Andrzcj, An Introduction to Mining Seismology, Seismology Press, Beijing, China, 1996.

[14] A. Keneti and B.-A. Sainsbury, "Review of published rockburst events and their contributing factors," Engineering Geology, vol. 246, pp. 361-373, 2018.

[15] D. Li, Z. Sun, T. Xie, X. Li, and P. G. Ranjith, "Energy evolution characteristics of hard rock during triaxial failure with different loading and unloading paths," Engineering Geology, vol. 228, pp. 270-281, 2017.

[16] L. T. Xie, P. Yan, W. B. Lu, M. Chen, and H. Wang, "Effects of strain energy adjustment: a case study of rock failure modes during deep tunnel excavation with different methods," KSCE Journal of Civil Engineering, vol. 10, no. 22, pp. 4143-4154, 2018.

[17] X. Feng, N. Zhang, and C. Lv, "Effects of interface damage resulting from the separation of layered strata on bolt anchoring systems," Shock and Vibration, vol. 2016, Article ID 2590816, 13 pages, 2016.

[18] S. Lee, T. P. Vo, H.-T. Thai, J. Lee, and V. Patel, "Strength prediction of concrete-filled steel tubular columns using Categorical Gradient Boosting algorithm," Engineering Structures, vol. 238, Article ID 112109, 2021.

[19] X. Feng, N. Zhang, G. Li, and G. Guo, "Pullout test on fully grouted bolt sheathed by different length of segmented steel tubes," Shock and Vibration, vol. 2017, Article ID 4304190, 16 pages, 2017.

[20] X. Kang, D. Guo, and Z. Lu, "Mechanism of roadway floor heave controlled by floor corner pile in deep roadway under high horizontal stress," Advances in Civil Engineering, vol. 2021, Article ID 6669233, 10 pages, 2021. 